\title{
Deficiência hídrica da cultura da soja na região de Dourados, MS
}

Carlos R. Fietz ${ }^{1} \&$ Mário A. Urchei²

\author{
1 Embrapa Agrop. Oeste. CP 661, CEP 79804-970, Dourados, MS. Fone: (67) 425-5122. Email: fietz@cpao.embrapa.br (Foto) \\ 2 Embrapa Agrop. Oeste. Email: urchei@cpao.embrapa.br
}

Protocolo $183-27 / 12 / 2001$

\begin{abstract}
Resumo: A fim de se determinar a deficiência hídrica da cultura da soja (Glycine Max), em duas épocas de semeadura, na região de Dourados, MS, elaborou-se o presente trabalho, cujo estudo se baseia em dados diários de precipitação pluvial e de outros elementos meteorológicos, utilizados na estimativa da evapotranspiração, de um período de 20 anos. A evapotranspiração de referência foi estimada pelo método Penman-Monteith e os dados meteorológicos foram coletados na Estação Meteorológica da Embrapa Agropecuária Oeste, em Dourados, MS. A deficiência hídrica da cultura da soja, calculada com base em um balanço hídrico climatológico diário seqüencial, foi considerada como a diferença entre a evapotranspiração da cultura e a evapotranspiração real. Os atributos físicos do solo foram definidos com base em curvas de retenção de um Latossolo Vermelho Distroférrico típico roxo. De maneira geral, a soja semeada em novembro apresentou maior deficiência hídrica que a semeada em dezembro. Na semeadura em novembro, os maiores déficits hídricos na soja ocorreram no estádio do segundo nó ao início do florescimento, enquanto na semeadura de dezembro as maiores deficiências de água ocorreram no início do florescimento ao início do enchimento de grãos. Houve deficiência hídrica em todos os subperíodos da cultura da soja, em todas as safras e em ambas as épocas de semeadura.
\end{abstract}

Palavras-chave: Glycine max, balanço hídrico, déficit hídrico, evapotranspiração, precipitação efetiva

\section{Water deficit in soybean cultivation in the region of Dourados, MS - Brazil}

\begin{abstract}
The aim of this paper is to determine the water deficiency for soybean (Glycine max) during two sowing periods, in Dourados, Mato Grosso do Sul, Brazil. The study is based on daily rainfall data and meteorological parameters, used to estimate the evapotranspiration. The reference evapotranspiration was estimated by the Penman-Monteith method. The meteorological data of 20 years, were collected at the Embrapa Meteorological Station, in Dourados. The soybean water deficiency was calculated through a daily sequential water balance and considered as the difference between the maximum crop evapotranspiration and the real evapotranspiration. The physical attributes of the soil were estimated from the retention curves of a Red Latosol. During most of the years, the November sown soybean presented larger water deficiency than the December sown soybean: the November soybean presented larger deficits from the second node stage to the beginning of the bloom, while in the December soybean, the larger water deficits occurred from the beginning of bloom to the beginning of grain formation. There was water deficiency in all soybean subperiods and every year for both the sowing periods.
\end{abstract}

Key words: Glycine max, water balance, water deficit, evapotranspiration, effetive precipitation

\section{INTRODUÇÃO}

A região de Dourados, MS, situa-se numa das principais áreas de produção agrícola do Brasil, onde são cultivados anualmente cerca de 600 mil hectares com soja (Glycine max). A ocorrência de déficit hídrico é uma das principais causas de perdas agrícolas na região, pois na safra de verão ocorrem, com freqüência, veranicos e estiagens, devido a grande demanda evapotranspirativa e pela distribuição irregular das chuvas (Fietz et al., 2001).
No Rio Grande do Sul é comum a ocorrência de deficiência hídrica durante o ciclo de desenvolvimento da soja, sendo esse um dos principais fatores limitantes à obtenção de elevados rendimentos de grãos (Matzenauer et al., 1998). Mota et al. (1996) verificaram que a cultura da soja, em todas as regiões climáticas desse Estado, necessita de irrigação em qualquer época de semeadura recomendada, para todos os grupos de maturação e subperíodos avaliados.

Vários estudos comprovam que o período reprodutivo da soja é o mais sensível ao déficit hídrico; no entanto, não há 
consenso entre os autores quanto ao(s) estádio(s) mais crítico(s) à baixa umidade do solo. A necessidade de água na soja aumenta com o desenvolvimento da planta, atingindo o máximo no florescimento-enchimento de grãos e decresce depois desse estádio fenológico. Déficits hídricos expressivos durante esses estádios provocam alterações fisiológicas na planta, causando a queda prematura de folhas e flores e abortamento de vagens e também reduz a produtividade de grãos (Embrapa, 1999).

Doorenbos \& Kassam (1994) consideram que os períodos de florescimento e de formação da colheita da soja são os mais sensíveis ao déficit hídrico, particularmente a última parte do período de florescimento e o período de desenvolvimento da vagem.

De acordo com Neumaier et al. (2000) a ocorrência de estresse hídrico em todo o subperíodo de início de enchimento de grãos e início do estádio de grãos verdes, pode reduzir drasticamente o rendimento da soja, pois quase metade dos nutrientes necessários ao enchimento de grãos provém do solo e da fixação biológica de nitrogênio. Segundo esses autores, durante a fase de enchimento de grãos a ocorrência de deficiências hídricas, acompanhadas de altas temperaturas, pode causar enrugamento dos grãos de cultivares sensíveis, reduzindo o rendimento e a qualidade da soja.

Doss et al. (1974) observaram que o estádio de vagem completamente desenvolvida foi o mais crítico da soja à deficiência hídrica. Kadhem et al. (1985) verificaram que o período reprodutivo, da metade dos estádios de desenvolvimento da vagem até um pouco antes dos estádios de formação de grãos, foi crítico para a resposta da soja à irrigação. Porém Doorenbos \& Kassam (1994) afirmaram que o teor de água no solo, durante a germinação, não deve exceder $85 \%$ nem ficar abaixo de $50 \%$ da água disponível. Segundo os autores, esse seria o nível de esgotamento permissível para o manejo da irrigação em condições médias de evapotranspiração $\left(5 \mathrm{a} \mathrm{mm} \mathrm{d}^{-1}\right)$.

Considerando a importância e as poucas informações existentes sobre deficiência hídrica da soja cultivada na região de Dourados e a influência da época de semeadura na necessidade de água das culturas, realizou-se este trabalho cujo objetivo foi determinar o déficit hídrico da soja, em duas épocas de semeadura.

\section{MATERIAL E MÉTODOS}

Este trabalho se baseou em dados de 20 anos de precipitação pluvial e de outros elementos meteorológicos utilizados para estimativa da evapotranspiração de referência (temperatura, umidade relativa do ar, número de horas de brilho solar e velocidade do vento) coletados na Estação Agrometeorológica da Embrapa Agropecuária Oeste de Dourados, MS, cujas coordenadas geográficas são: $22^{\circ} 14^{\prime} \mathrm{S}, 54^{\circ} 49^{\prime}$ W e altitude média de $452 \mathrm{~m}$. O clima da região é o Cwa (mesotérmico úmido, com verão chuvoso), de acordo com a classificação de Köppen.

A deficiência hídrica da soja foi estimada por um balanço hídrico climatológico diário seqüencial, através do programa computacional SISDA - Sistema de Suporte à Decisão Agrícola (Mantovani et al., 1997). A deficiência hídrica da cultura, em cada subperíodo, foi considerada como o somatório das diferenças diárias entre a evapotranspiração máxima e a evapotranspiração real da cultura. O SISDA calcula a evapotranspiração real com base na umidade atual, na disponibilidade hídrica e no número de camadas do solo.

A evapotranspiração máxima da cultura foi obtida pelo produto da evapotranspiração de referência $\left(\mathrm{ET}_{0}\right)$ e o coeficiente de cultivo. As estimativas de $\mathrm{ET}_{0}$ foram obtidas pelo método Penman-Monteith, conforme Allen et al. (1998):

$$
\mathrm{ET}_{0}=\frac{0,408 \Delta\left(\mathrm{R}_{\mathrm{n}}-\mathrm{G}\right)+\gamma \frac{900}{(\mathrm{~T}+273)} \mathrm{U}_{2}\left(\mathrm{e}_{\mathrm{s}}-\mathrm{e}_{\mathrm{a}}\right)}{\Delta+\gamma\left(1+0,34 \mathrm{U}_{2}\right)}
$$

em que:

$\mathrm{ET}_{\mathrm{o}}$ - evapotranspiração de referência, $\mathrm{mm} \mathrm{d}^{-1}$

$\Delta$ - declividade da curva de saturação do vapor d'água, $\mathrm{kPa}^{\circ} \mathrm{C}^{-1}$

$\mathrm{Rn}$ - saldo de radiação, $\mathrm{MJ} \mathrm{m}^{-2} \mathrm{~d}^{-1}$

$\mathrm{G}$ - fluxo de calor no solo, $\mathrm{MJ} \mathrm{m}^{-2} \mathrm{~d}^{-1}$

$\mathrm{e}_{\mathrm{s}}$ - pressão de saturação do vapor d'água, $\mathrm{kPa}$

$\mathrm{e}_{\mathrm{a}}$ - pressão real do vapor d'água, $\mathrm{kPa}$

$\gamma$ - constante psicrométrica, $0,0639 \mathrm{kPa}^{\circ} \mathrm{C}^{-1}$

$\mathrm{U}_{2}$ - velocidade média do vento a $2 \mathrm{~m}, \mathrm{~m} \mathrm{~s}^{-1}$

$\mathrm{T}^{2}$ - temperatura média diária, ${ }^{\circ} \mathrm{C}$

O saldo de radiação foi estimado em função do número de horas de brilho solar, temperatura e umidade do ar, conforme metodologia apresentada por Allen et al. (1998).

No cálculo do balanço hídrico, o programa considera na íntegra precipitações diárias inferiores a $25 \mathrm{~mm}$. Quando as chuvas são iguais ou superiores a esse valor, a precipitação pluvial efetiva é estimada em função da chuva total e da disponibilidade hídrica do solo, no dia de ocorrência e no anterior.

A deficiência hídrica da soja foi determinada para as épocas de semeadura recomendadas para a região de Dourados e se considerou 15 de novembro e 15 de dezembro como as datas de plantio. A duração dos subperíodos da cultura foi definida com base em observações de dois anos, realizadas na Embrapa Agropecuária Oeste, em Dourados, de cultivares de ciclo precoce médio, predominantes na região (Tabela 1). Os estádios de desenvolvimento foram definidos segundo a metodologia apresentada por Fehr \& Caviness (1977), sendo o ciclo da

Tabela 1. Duração dos subperíodos, coeficientes de cultivo $\left(\mathrm{K}_{\mathrm{c}}\right)$ e profundidade efetiva do sistema radicular $\left(\mathrm{P}_{\mathrm{e}}\right)$ da cultura de soja, em duas épocas de semeadura

\begin{tabular}{|c|c|c|c|c|}
\hline \multirow{3}{*}{ Subperíodo ${ }^{*}$} & \multicolumn{2}{|c|}{ Duração (d) } & \multirow{3}{*}{$\mathrm{K}_{\mathrm{c}}$} & \multirow{3}{*}{$\begin{array}{l}P_{c} \\
(\mathrm{~m})\end{array}$} \\
\hline & \multicolumn{2}{|c|}{ Semeadura } & & \\
\hline & $15 / 11$ & $15 / 12$ & & \\
\hline $\mathrm{S}$ a V2 & 20 & 20 & 0,35 & 0,15 \\
\hline V2 a R1 & 40 & 30 & 0,75 & 0,30 \\
\hline R1 a R5 & 25 & 25 & 1,07 & 0,40 \\
\hline R5 a R7 & 25 & 25 & 0,75 & 0,40 \\
\hline S a R7 & 110 & 100 & & \\
\hline
\end{tabular}

"S - Semeadura; V2 - Segundo nó; R1 - Início do florescimento; R5 - Início do enchimento de grãos R7 - Maturação fisiológica 
cultura dividido em quatro subperíodos de desenvolvimento, de forma similar ao trabalho realizado por Berlato et al. (1986).

Os coeficientes de cultivo e a profundidade do sistema radicular de cada subperíodo (Tabela 1) foram definidos conforme recomendações, respectivamente, de Doorenbos \& Kassam (1994) e Mantovani et al. (1997).

Os atributos físicos do solo utilizados no balanço hídrico foram definidos com base em seis curvas de retenção de água de um Latossolo Vermelho Distroférrico típico utilizadas no manejo da irrigação da área experimental da Embrapa Agropecuária Oeste (Tabela 2). Assumiu-se que no início do balanço hídrico o solo estava na sua capacidade de campo.

Tabela 2. Umidade do solo na capacidade de campo $\left(\mathrm{U}_{\mathrm{cc}}\right)$, no ponto de murcha $\left(\mathrm{U}_{\mathrm{pm}}\right)$ e densidade do solo $\left(\mathrm{D}_{\mathrm{s}}\right)$

\begin{tabular}{cccc}
\hline $\begin{array}{c}\text { Profundidade } \\
(\mathrm{m})\end{array}$ & $\begin{array}{c}\mathrm{U}_{\mathrm{CC}} \\
\left(\mathrm{kg} \mathrm{kg}^{-1}\right)\end{array}$ & $\begin{array}{c}\mathrm{U}_{\mathrm{PM}} \\
\left(\mathrm{kg} \mathrm{kg}^{-1}\right)\end{array}$ & $\begin{array}{c}\mathrm{D}_{\mathrm{S}} \\
\left(\mathrm{kg} \mathrm{m}^{-3}\right)\end{array}$ \\
\hline $0,00-0,20$ & 0,291 & 0,237 & 1,37 \\
$0,21-0,40$ & 0,309 & 0,259 & 1,36 \\
\hline
\end{tabular}

\section{RESULTADOS E DISCUSSÃO}

Na Tabela 3A e B são apresentados os valores de déficit hídrico da soja em 20 safras ou anos agrícolas, respectivamente, para semeaduras realizadas em 15 de novembro e 15 de dezembro. Analisando-as, percebe-se que ocorreu deficiência hídrica em todos os subperíodos e anos agrícolas, em ambas as épocas de semeadura. Os resultados foram similares aos de Mota et al. (1996) e Matzenauer et al. (1998), com a cultura da soja no Rio Grande do Sul, e confirmam que a irrigação na região de Dourados, em caráter complementar, é tecnicamente justificada pelos altos índices de déficit hídrico que podem ocorrer nas safras de verão (Fietz et al., 2001).

Na semeadura de novembro, a deficiência hídrica variou de 50,7 (safra 1996/97) a 174,6 mm (safra 1990/91) com média de 100,4 mm (Tabela 3). Apenas em três safras (1980/81, 1983/84 e 1996/97) os déficits máximos ocorreram no subperíodo compreendido entre o início do enchimento de grãos e a maturação fisiológica (R5-R7). Na maioria dos anos agrícolas, os índices máximos ocorreram do início do florescimento ao início do enchimento de grãos (R1-R5) e, principalmente, na fase vegetativa, do segundo nó ao início do florescimento (V2R1). Esse comportamento se deve, provavelmente, ao fato desses subperíodos ocorrerem quase que integralmente em dezembro e janeiro, meses que apresentam a maior demanda evapotranspirativa na região de Dourados (Oliveira et al., 2000).

Considerando-se 15 de dezembro como época de semeadura, o déficit hídrico da soja variou de 26,9 (safra 1995/96) a 148,0 mm (safra 1989/90), com média de 84,6 mm (Tabela 3B). Os valores máximos de deficiência hídrica ocorreram nos subperíodos do segundo nó ao início do florescimento (V2R1) e, principalmente, do início do florescimento ao início do enchimento de grãos (R1-R5). Esse resultado se deve, provavelmente, ao fato do subperíodo R1-R5 ser o de maior consumo hídrico da soja (Berlato et al., 1986) e, ainda, à redução do período vegetativo da cultura, em relação à semeada em novembro.
Tabela 3. Deficiência hídrica (mm) da soja semeada em 15 de novembro (A) e 15 de dezembro (B) na região de Dourados, em 20 anos agrícolas, nos subperíodos compreendidos entre a Semeadura (S) e o Segundo nó (V2), V2 e o Início do florescimento (R1); R1 ao Início e o enchimento de grãos (R5) e R5 e a Maturação fisiológica (R7)

\begin{tabular}{llllll}
\hline \multirow{2}{*}{ Ano Agrícola } & \multicolumn{5}{c}{ Subperíodo } \\
\cline { 2 - 6 } & $\mathrm{S}$ a V2 & V2 a R1 & R1 a R5 & R5 a R7 & S a R7 \\
\hline
\end{tabular}

A. Semeadura em 15 de Novembro

\begin{tabular}{|c|c|c|c|c|c|}
\hline $1979 / 80$ & 1,6 & 28,9 & 56,8 & 13,7 & 101,0 \\
\hline $1980 / 81$ & 1,4 & 23,8 & 20,4 & 28,3 & 73,9 \\
\hline $1981 / 82$ & 1,1 & 23,8 & 50,0 & 3,2 & 78,1 \\
\hline $1982 / 83$ & 1,5 & 39,3 & 31,4 & 8,0 & 80,2 \\
\hline $1983 / 84$ & 2,0 & 17,5 & 20,9 & 33,2 & 73,6 \\
\hline $1984 / 85$ & 1,1 & 26,9 & 87,2 & 20,2 & 135,4 \\
\hline $1985 / 86$ & 4,5 & 120,4 & 20,9 & 12,5 & 158,3 \\
\hline $1986 / 87$ & 2,2 & 33,9 & 15,6 & 17,2 & 68,9 \\
\hline $1987 / 88$ & 4,2 & 19,9 & 31,6 & 15,6 & 71,3 \\
\hline $1988 / 89$ & 2,2 & 26,3 & 17,1 & 8,7 & 54,3 \\
\hline $1989 / 90$ & 2,2 & 15,2 & 56,6 & 47,8 & 121,8 \\
\hline 1990/91 & 3,7 & 73,6 & 59,1 & 38,2 & 174,6 \\
\hline 1991/92 & 5,6 & 35,2 & 91,5 & 14,9 & 147,2 \\
\hline $1992 / 93$ & 0,8 & 59,6 & 56,7 & 20,5 & 137,6 \\
\hline $1993 / 94$ & 2,2 & 58,1 & 39,5 & 14,1 & 113,9 \\
\hline $1994 / 95$ & 2,9 & 33,9 & 28,5 & 24,1 & 89,4 \\
\hline $1995 / 96$ & 7,2 & 35,7 & 12,3 & 5,5 & 60,7 \\
\hline $1996 / 97$ & 7,1 & 11,6 & 2,4 & 29,6 & 50,7 \\
\hline $1997 / 98$ & 0,2 & 76,1 & 40,8 & 8,9 & 126,0 \\
\hline $1998 / 99$ & 3,2 & 16,5 & 60,3 & 11,9 & 91,9 \\
\hline Média & 2,8 & 38,8 & 40,0 & 18,8 & 100,4 \\
\hline Mínimo & 0,2 & 11,6 & 2,4 & 3,2 & 50,7 \\
\hline Máximo & 7,2 & 120,4 & 91,5 & 47,8 & 174,6 \\
\hline Desvio-padrão & 2,1 & 30,8 & 26,4 & 12,9 & 39,0 \\
\hline B. Semeadura e & $15 \mathrm{de}$ & zembro & & & \\
\hline $1979 / 80$ & 0,5 & 40,4 & 32,8 & 28,7 & 102,4 \\
\hline $1980 / 81$ & 1,1 & 5,4 & 48,4 & 24,0 & 78,9 \\
\hline $1981 / 82$ & 0,9 & 30,2 & 7,9 & 2,6 & 41,6 \\
\hline $1982 / 83$ & 2,2 & 23,0 & 19,4 & 8,1 & 52,7 \\
\hline $1983 / 84$ & 1,3 & 8,1 & 53,2 & 31,7 & 94,3 \\
\hline $1984 / 85$ & 1,5 & 52,1 & 51,6 & 5,9 & 111,1 \\
\hline $1985 / 86$ & 5,9 & 21,9 & 19,9 & 27,6 & 75,3 \\
\hline $1986 / 87$ & 5,2 & 10,0 & 31,1 & 30,9 & 77,2 \\
\hline $1987 / 88$ & 1,5 & 11,4 & 35,1 & 10,5 & 58,5 \\
\hline $1988 / 89$ & 1,7 & 4,7 & 22,7 & 9,2 & 38,3 \\
\hline $1989 / 90$ & 1,8 & 21,8 & 77,3 & 47,1 & 148,0 \\
\hline 1990/91 & 6,0 & 32,0 & 64,1 & 42,9 & 145,0 \\
\hline $1991 / 92$ & 2,1 & 57,8 & 40,5 & 4,6 & 105,0 \\
\hline $1992 / 93$ & 2,5 & 34,9 & 33,7 & 20,0 & 91,1 \\
\hline $1993 / 94$ & 3,5 & 42,3 & 24,4 & 36,9 & 107,1 \\
\hline $1994 / 95$ & 1,0 & 10,3 & 45,7 & 25,4 & 82,4 \\
\hline $1995 / 96$ & 2,4 & 4,4 & 13,8 & 6,3 & 26,9 \\
\hline $1996 / 97$ & 0,6 & 3,7 & 48,7 & 26,5 & 79,5 \\
\hline $1997 / 98$ & 11,8 & 39,3 & 18,8 & 15,5 & 85,4 \\
\hline $1998 / 99$ & 1,0 & 39,7 & 27,0 & 23,6 & 91,3 \\
\hline Média & 2,7 & 24,7 & 35,8 & 21,4 & 84,6 \\
\hline Mínimo & 0,5 & 3,7 & 7,9 & 2,6 & 26,9 \\
\hline Máximo & 11,8 & 57,8 & 77,3 & 47,1 & 148,0 \\
\hline Desvio-padrão & 3,2 & 17,9 & 19,7 & 14,0 & 34,6 \\
\hline
\end{tabular}

Em todas os anos agrícolas e em ambas as épocas de semeadura, os menores valores de deficiência hídrica ocorreram da semeadura até o estádio do segundo nó, o que pode ser justificado pelo baixo índice de área foliar das plantas de soja desse subperíodo, resultando num baixo consumo de água 
(Matzenauer et al., 1998); além disso, considerou-se que na semeadura o solo estava com sua capacidade máxima de armazenamento de água.

A deficiência hídrica total da soja nos diversos anos agrícolas encontra-se na Figura 1 onde verifica-se, na maioria das safras, maior déficit hídrico na semeadura de novembro, ocorrendo as maiores diferenças nas safras 1985/86 (83,0 mm), 1992/93 (46,5 mm) e 1997/98 (40,7 mm). Apenas em seis anos agrícolas o déficit hídrico da soja semeada em dezembro superou a cultivada em novembro. Esses resultados são devidos, provavelmente, ao fato da soja semeada em novembro ter apresentado a maior parte do desenvolvimento dos seus estádios críticos à deficiência hídrica nos meses de elevada demanda evapotranspirativa (dezembro e janeiro) havendo, portanto, ocorrência simultânea dos períodos de maior necessidade de água pela cultura com os de elevada demanda hídrica. Portanto, na região de Dourados, com relação ao consumo hídrico, a semeadura da soja em dezembro seria mais favorável que a de novembro.

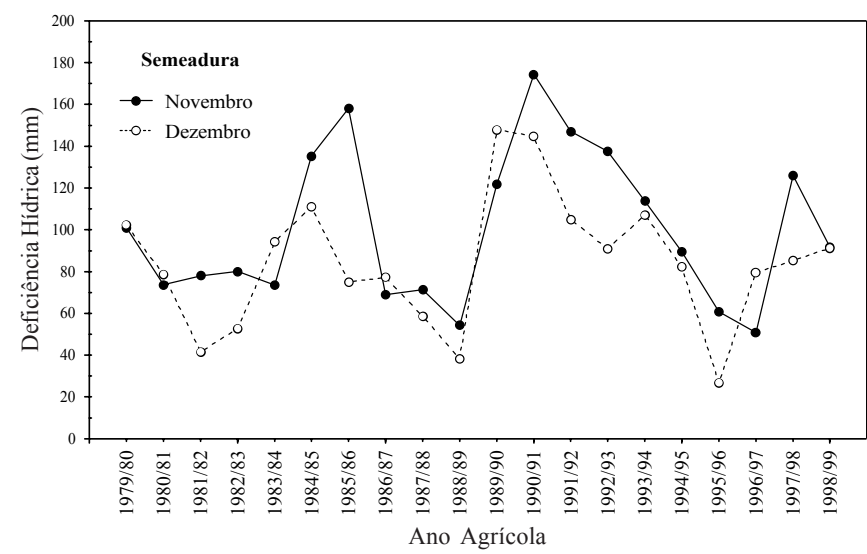

Figura 1. Deficiência hídrica total da cultura da soja na região de Dourados, MS, nos anos agrícolas de 1979/80 a 1998/99

\section{CONCLUSÕES}

1. Na maioria dos anos agrícolas constatou-se maior déficit hídrico na soja semeada em novembro, em relação à cultivada em dezembro.

2. Os valores máximos de deficiência hídrica na soja, semeada em novembro, ocorreram na fase vegetativa, do estádio do segundo nó ao início do florescimento.

3. Os maiores valores de déficit hídrico na soja semeada em dezembro, ocorreram do início do florescimento ao início do enchimento de grãos.

4. Houve deficiência hídrica em todos os subperíodos da soja, em todas as safras e em ambas as épocas de semeadura.

\section{LITERATURA CITADA}

Allen, R.G.; Pereira, L.S.; Raes, D.; Smith, M. Crop evapotranspiration: Guidelines for computing crop water requirements. Rome: FAO, 1998. 297p. FAO. Irrigation and Drainage Paper, 56
Berlato, M.A.; Matzenauer, R.; Bergamaschi, H. Evapotranspiração máxima da soja e relações com a evapotranspiração calculada pela equação de Penman, evaporação do tanque "Classe A" e radiação solar. Agronomia Sulriograndense, Porto Alegre, v.22, n.2, p.243-259, 1986.

Doorenbos, J.; Kassam, A.H. Efeito da água no rendimento das culturas. Campina Grande: UFPB/FAO, 1994. 306p. FAO. Estudos: Irrigação e Drenagem, 33

Doss, B.D.; Pearson, R.W.; Rogers, H.T. Efect of soil water stress at various growth stages on soybean yield. Agronomy Journal, Madison, v.66, n.2, p.297-299, 1974.

EMBRAPA - Empresa Brasileira de Pesquisa Agropecuária. Recomendações técnicas para a cultura da soja na região central do Brasil 1999/2000. Londrina: Embrapa Soja, Documentos, 132; Dourados: Embrapa Agropecuária Oeste, Documentos, 5, 1999. 226p.

Fehr, W.R.; Caviness, C.E. Stages of soybean development. Ames: Iowa State University of Science and Technology, 1977. 11p. Special Report, 80

Fietz, C.R.; Urchei, M.A.; Frizzone, J.A. Probabilidade de ocorrência de déficit hídrico na região de Dourados (MS). In: Congresso Brasileiro de Engenharia Agrícola, 30, 2001, Foz do Iguaçu. Anais... Foz do Iguaçu: Sociedade Brasileira de Engenharia Agrícola, 2001. CD-Rom

Kadhem, F.A.; Specht, J.E.; Williams, J.H. Soybean irrigation serially timed during stages R1 to R6. Agronomic responses. Agronomy Journal, Madison, v.77, n.2, p.291-298, 1985.

Mantovani, E.C.; Costa, L.C.; Leal, B.G. SISDA - Sistema de suporte a decisão agrícola. In: Congresso de Informática Aplicada à Agropecuária e Agroindústria, 1, e Workshop on Supply Chain Management in Agribusiness, 1997, Belo Horizonte. Agrosoft 97. Juiz de Fora: Softex- Agrosoft, 1997. CD-Rom

Matzenauer, R.; Barni, N.A.; Machado, F.A.; Rosa, F.S. Análise agroclimática das disponibilidades hídricas para a cultura da soja na região do Planalto Médio do Rio Grande do Sul. Revista Brasileira de Agrometeorologia, Santa Maria, v.6, n.2,p.263-275, 1998.

Mota, F.S.; Agendes, M.O.O.; Alves, E.G.P.; Signorini, E. Análise agroclimática da necessidade de irrigação da soja no Rio Grande do Sul. Revista Brasileira de Agrometeoro-logia, Santa Maria, v.4, n.1, p.133-138, 1996.

Neumaier, N.; Nepomuceno, A.L.; Farias, J.R.B.; Oya, T. Estádios de desenvolvimento da cultura de soja. In: Bonatto, E.R. (eds.). Estresses em soja. Passo Fundo: Embrapa Trigo, 2000, cap.1, p.19-44.

Oliveira, H. de; Urchei, M.A.; Fietz, C.R. Aspectos físicos e socioeconômicos da bacia hidrográfica do Rio Ivinhema. Dourados: Embrapa Agropecuária Oeste, 2000. 52p. Documentos, 25 